Participatory Television: Convergence, Crowdsourcing, and Neoliberalism

Adam Fish, $\mathrm{PhD}$

Sociology Department

Lancaster University

Forthcoming in 2013

Communication, Culture, and Critique 


\section{Participatory Television: Convergence, Crowdsourcing, and Neoliberalism}

\section{Introduction}

In this article I assess theories of internet-enabled public participation as they have been devised to explain the audience participatory projects of Current TV, a global cable and satellite television and internet video network once partially programmed by non-fiction videos submitted by viewers. I explore how each author's theory of participation-convergence (Jenkins 2006), crowdsourcing (Howe 2008), and neoliberal participation (Hands 2011)--variously fails and succeeds to historically and culturally situate Current TV within its socio-cultural context as mixed mission and market digital social entrepreneur.

To explore this issue I analyze five historical phases of Current TV: INdTV (2000-2004), Digital Correspondents (DC) (2004-2005), Viewer-Created Content (VC2) (2005-2008), Current.com (2008-2009), Hollywood (2009-) Throughout this history, one sees Current TV progress as a formal social enterprise engineering an organized public and struggle with a mission to democratize media production within an economy based on neoliberal principles. I conclude by introducing digital social entrepreneurship to describe the historically variable mix of mission and market values inherent in social activity.

\section{Methodology and Reflexivity}

I was being driven in a taxi to my hotel in Nicosia, Cyprus when I peered out the window and saw a scrappy tent encampment under olive trees and, oddly enough, a large and tattered Iraqi flag. I immediately asked the driver to stop and I got out with my videocamera, ran across the street, and I was suddenly in the "green zone" that separates the Greek from the Turkish Cyprus. UN security towers hovered over me, the deflated tents, broken chairs, and four Iraqi men. I introduced myself and they diligently and proudly told me their story on mini-DV tape. They smuggled themselves here and camping out protesting for asylum or a work visa. I spent hours that evening and the next day collecting their stories of being scientists, teachers, artists, and military personnel who were secular and harassed by the religious fundamentalist overlords of Baghdad recently liberated out of the chaos of occupation.

I was nervous carrying all of this footage from the green zone to the United States and I made it through customs and back to Los Angeles. I had collected about 15 interviews and 5 hours of b-roll footage for the short documentary Divided Cyprus (Fish 2008) and four interviews and an hour of b-roll for Secular Iraqi Refugees (Fish 2007). I edited this footage into two 5-7 minute short documentaries and uploaded them onto current.tv. Current used their online video site to solicit, display, and decide to purchase short documentaries from viewer-created content (VC2) producers. The response to my short documentaries within the online VC2 community was positive and soon Andrew Fitzgerald, the manager of the Collective Journalism (CJ) department, was requesting a phone call. He wanted the short documentaries or what Current TV called "pods" and pay me $\$ 750$ for each. The vision I had of myself as a rogue cosmopolitan journalist was 
going to be complete, not only had I been to one warzone and recorded the stories from another, I would be bringing these stories to television. These stories would provoke dialogue amongst viewers about the negative human affects of war, I hoped.

Two of the Iraqi refugees, Jawad and Ammar, upon seeing the pod they are in online, left comments on the online video post updating the audience about their situation. Amongst other things, Ammar wrote that they "came here seeking refuge into this country to escape death in our country." Fitzgerald, upon seeing these Iraqi refugees comment on my pod, made a video himself and uploaded. Fitzgerald discussed the refugees' comments and how this was Current's fifth pod on Iraqi refugees from all over the world including Kurdistan, Jordan, Syria, Sweden, and now Cyprus. Fitzgerald's video and my pod were shown on television. This recursive loop between a VC2 producer, a diverse and engaged audience, a Current TV employee, and Iraqi refugees shows the power of a multiplatform and interactive approach to television journalism. We had produced a small public sphere on the issue of war diaspora and it felt good.

This example of reflexivity introduces my professional experience as a freelance producer for Current TV. Grounded in my personal work-based subjectivity, this article is a critical historical account of the various discourses and practices at work at one cable and satellite television news network (Jarzombek 1999). In this respect this project is in the tradition of communication historiography that revisits and reviews instances of how technological transformation instigates cultural interventions. This critical historiography in communication studies draws from the work of communication justice scholars (Halleck 2002, Kellner 1990, Klinenberg 2007, McChesney 2008, Streeter 1996, Wu 2010). While this article is partially based in interviews and participant observation, it is not an ethnography in the anthropological sense.

From 2007-2009, I worked as a freelance documentary producer for Current TV. In the course of my work I produced 16 documentaries financed by Current TV ${ }^{1}$. Since 2007, I have been an active participant on their social media website. Beginning in 2008, I initiated an interview campaign with present and former employees particularly engaged in user-generated content, logging over 30 interviews. I have spent many hours of the phone and in person discussing the production assets of my documentaries with Current TV creative executives and editors. I have visited both offices in Los Angeles and the headquarters in San Francisco several times. Current TV employees have become my friends and I have watched their careers diversify and expand into the start-up, freelance, film festival, and commercial television workworlds. Outside of Current TV, I have conducted field visits and interviews with workers throughout the related industries of cable television and internet television. Other subjects include video workers at CNN, Blip.tv, Al Jazeera, Democracy Now!, Witness, Free Speech TV, and Google's Next New

\footnotetext{
${ }^{1}$ My Current TV documentaries include: Belfast is Still a Divided City (2009), Nike's Native American Nation (2009), Outsourcing Your Parents to Mexico (2008), Skywalking Native Americans (2008), Sin City Ghost Town (2008), Rewriting LA History (2008), Kyrgyzstan Revolution (2008), Bible Science (2008), Split/Cyprus (2008), Racially Segregated Graduation at UCLA (2007), Secular Iraqi Refugees (2007), Confessions of the Burning Man Arson (2007), Street Styles LA (2007), Buddhist Sacred Land Battle (2007), Tantric Tourists (2007), and Me and My Medical Marijuana (2007). Documentaries were aired on DIRECTV 358, DISH Network 196, Comcast 107 or 125, Time Warner 103 or 142, and current.com.
} 
Networks. Thus, in the tradition of multisited anthropology, my methodology included following the people and their ideas (Marcus 1995). In the process, I collected historical information useful to engage with existing theories of crowdsourcing, neoliberalism, and convergence. Equally important, these professional and personal experiences allowed me the access and empathy required to conduct this research.

In light of these professional experiences, I am going to critically assess theories about Current TV's participatory regimes. With the exception of Howe (2008), several scholars have written about Current TV but none have conducted any interviews or participant observation.

\section{Participation and the Collaboration between Amateurs and Professionals}

Participation, as I am discussing it, refers to amateurs having the competencies or access to engage with otherwise closed socio-technical systems, either in direct consort or as non-networked individuals in a public. Thus, by participation I refer to amateurs acting together individually, collectively, or with organizations in fields otherwise dominated by gatekeepers or professionals. This type of amateur participation has a long history. Piracy, for example, is a type of cultural production outside "professional" craft. Unofficial printing and science experimenting, intellectual property violations, software and DVD re-production, are all forms of piratical and amateur participation in otherwise professional fields (Johns 2009). Most communications technologies originate as amateur experiments. Amateur participation initiated the industries of radio, cable television, video production, and personal computers (Wu 2010). Later these communications tools are professionalized and the pioneering amateurs are excluded.

The differences between amateurs and professionals, like the contrasts between consumers and producers are collapsing leading some to say that a new form of capitalization might be emerging (Benkler 2011, Ritzer and Jurgenson 2010). I am more prone to seeing these forms of collaboration as embedded within present dominant forms of surplus generation. Present explicit forms or citizen participation within assemblages of television are overdetermined by neoliberalism. And yet, this analysis of Current TV expose the details of the slippages that occur within the neoliberal system allowing for cultural interventions--however truncated or interpellated by neoliberal practices those instances of openness may be.

The internet has enabled new forms of collaboration and participation. However, the varieties of participation, the impact of this civic participation, and how values and institutions impact the applications of this participation are yet to be fully understood. On the one hand are scholars who believe that the internet is liberating more virtuous sharing (Benkler 2011, Benkler and Nissenbaum 2006) and collaboration (Shirky 2010). On the other hands, scholars think that amateur participation is exploitative (Terranova 2009), uncreative (Lanier 2010), or diluting the quality of our journalism and therefore negatively impacting democratic society (Keen 2007). Most of this scholarship is not based in field observations and therefore retains a polemicism usually associated with theoretical speculation as opposed to interpretations based in empiricism. However, these 
scholars do excellent work defining the polemic parameters of internet-enabled participation. That is required are methods that reveal the discursive tensions at the center of those polemics.

Since the emergence of a user-friendly and writerly internet, participation has been both celebrated and critiqued. Following the work of Fish and Srinivasan (2011) and Carpentier (2009), this article attempts to describe internet-enabled participation empirically. In order to exhibit the variety of forms of participation possible, five theories in total are discussed in this paper. The first two theories, 1) "FSE-OP" or the ways formal social enterprises (FSEs) and organized publics (OPs) create the conditions for participation (Fish et al. 2011) and 2) implicit and explicit participation (Schafer 2011), are used throughout to interrogate three theories of internet-enabled participation drawn specifically from scholarship on Current TV: convergence (Jenkins 2006), crowdsourcing (Howe 2008), and neoliberal participation (Hands 2011) ${ }^{2}$.

\section{Formal Social Enterprises and Organized Publics}

In order to understand the variety of forms of participation we designed a guidebook which identified two species flourishing in the internet ecology: "formal social enterprises" (FSEs) which include firms and non-profits that aggregate or capitalize on participation as well as the "organized publics" (OPs) the enterprises foster or from which they emerge (Fish et al. 2011). These two types share a vertical or inverted relationship. In the "formal social enterprise" model, power comes down from visionary CEOs and charismatic NGO directors to provoke rabid social media production. In the "organized publics" model a viable movement foments amongst grassroots makers that percolates upwards towards the formation of semi-elitist institutions. The FSE-OP model is similar to the notion of convergence culture that is also a "complex relation between top-down corporate media and bottom-up participatory culture" (Jenkins 2006: 243). These distinctions assist the scholar of participation in articulating the fundamental social relations and formations in any internet-enabled participatory project.

Another set of general terms is necessary to define before embarking on the critique: explicit and implicit participation (Schafer 2011).

\section{Implicit and Explicit Participation}

\footnotetext{
2 Two concepts, while conceived in light of lengthy discussions of Current TV, will not be discussed: produsage (Bruns 2008), the conflation of producer and user, and republican communication (Hamilton and Heflin 2011), how firms manage user-generated video through contests. Bruns's (2008) research inaccurately depicts Current TV not as a television network but as a video filesharing site, a mischaracterization that negates his conclusions based on an over-emphasis on the importance of internet network "neutrality" or the non-discriminatory principle of internet traffic governance. Hamilton and Heflin (2011) claim to focus on Current TV's practices but in their failure to conduct participant observation they over-emphasize an issue my Current TV subjects never stated as a dominant value: competition amongst freelance producers. Current TV has also been mentioned in reference to the theory of wikinomics (Tapscott and Williams 2008) and prosumption (Ritzer and Jurgenson 2011)--both relatively optimistic about the economics of internet-enabled participation.
} 
Schafer (2011) outlines three forms of computer or internet-enabled participation: modification, explicit participation, and implicit participation. Each form of participation emerges from organized publics (OPs) or is in reaction to formal social enterprises (FSEs). Schafer's emphasis on how the affordances of computers and networks impact participation makes his delineation of modification, implicit, and explicit participation reliably based in materiality.

In Schafer's (2011) model, modification is the hacking of physical devices such as Xboxs or more traditional software modding. Of the three types, the maximum amount of agency is exerted in modifications. The second is explicit participation, where subjects actually make original media--this could be a digital documentary, a blog, or a musical mash-up or remix. Explicit participation is agency exerted in acts motivated by ambition, community involvement, or for professional or personal growth. Thirdly, is implicit participation, the subjectively lackadaisical or algorithmically automated forms of participation such as "liking" on Facebook, building playlists on YouTube, or simply conducting Google searches that help Google fine tune and target its search and advertising machinery. This explicit and implicit duality models our earlier differentiation between voluntary and involuntary participation (Fish et al. 2011). With the theories of formal social enterprises, organized publics, and implicit and explicit participation we can now begin to interrogate how three theories of participation are applied at Current TV.

\section{Convergence Culture}

The socio-technical and historical moment for internet-enabled participation is accurately described as convergence culture: "where old media and new media collide, where grassroots and corporate media intersect, where the power of the media producer and the power of the media consumer interact in unpredictable ways" (Jenkins 2006: 259-260). This description of convergence is distinct from the argument put forth by John T. Caldwell, that convergence articulates the attempts of media corporations to corner new markets (2004). On the one hand are powerful elites, some of them from for-profit formal social enterprises, exploiting conglomeration, to sell and cement their hold on the media and the audiences (Jenkins 2008: 243). On the other hand, are organized publics who are provoking formal social enterprises to respond to new participatory desires.

Jenkins is a self-professed "critical utopian" that sees greater participation as a benefit to society and a driving force for positive social change. However, his hopefulness ends into two dead-ends. He drops explicit participation in exchange for a type of implicit participation or active consumerism. The type of cultural change Jenkins sees is not directed at improving democracy but obliquely in the realm of changing producerconsumer relations through implicit participation in consumer culture. Secondly, Jenkins puts the responsibility for social change on the active consumer as opposed to the formal social enterprise. Current TV, from its inception saw its responsibility as a formal social enterprise differently. Current TV is an excellent example of explicit participation provoked by firms or formal social enterprises for political purposes. Current TV saw 
itself in a social relationship with organized publics of active producers to create both profit and to instigate political purpose.

In a following critical historiographical case study, I will answer questions in reference to convergence participation, including: Is political action outside of consumerism possible? Will formal social enterprises as well as organized publics advocate for participatory culture?

\section{Crowdsourcing}

In direct contrast to "consumption communities" based on implicit participation, is "crowdsourcing," an explicit form of participation by which formal social enterprises outsource labor not overseas but to anyone anywhere with an internet connection. The coiner of the term (Howe 2008), prominently features Current TV as a key example of a formal social enterprise that attempted to engineer an organized public. Crowdsourcing, in Howe's definition, is explicit--the production of short documentaries--not implicit participation--such as the re-blogging of news posts.

Howe is not the only scholar of crowdsourcing. Kperogi (2011) asks this question: Can user-generated video news content, promoted and contained by a corporation, constitute an alternative or resistance to mainstream media? The question's asking portends a new era of realistic criticism of the once ballyhooed liberatory capacities of "peer production" and "participatory culture." Investigating CNN's crowdsourced video project iReport, Kperogi's answer is a resounding no. CNN's iReport project to stimulate and aggregate user-generated news is not an alternative threat to hegemonic news but instead plays into the economic and hegemonic designs of the non-fiction industrial complex. Kperogi's (2011) assessment provides an excellent context for understanding Current TV and its crowdsourcing initiatives.

Current TV created a way for explicit participants to upload video to Current TV's servers, have those videos be judged by peers, purchased, and possible screened on their cable television network. In Howe's (2008) account, the engineering of this explicitly participatory organized public was challenged when Current TV neglected to personally interactive with the participants. Current TV employees eventually learned from their mistakes and began to encourage, aggregate, and distribute what Current TV calls "viewer-created content" (VC2) and later contributions to current.com, their online news aggregator. As you will read below, Current TV moved from an explicit to an implicit form of participation as they tried to maximize participation by "lowering the bar" to entry. In this move the critical role of online community managers within the formal social enterprise is highlighted.

In a following critical historiographical case study, I will answer the questions in reference to crowdsourcing participation, including: Can organized publics be engineered? What role do gatekeepers such as online community managers have in the popularization and promotion of participatory culture? 


\section{Neoliberal Participation}

From the perspective of those following Milton Friedman, neoliberal policy is focused on free markets and small to non-existent governments. The easily observable results of neoliberal theory in state politics are deregulation, worker precarity, and the erosion of public spending. But this does not describe the cultural (Comaroff and Comaroff 2000), functionally systemic (Harvey 2005), or governmentality of neoliberalism. Neoliberal governmentality refers to the flexible marketization of the state and the subsequent flexible and market interprellation of social relations. With its focus on the agency of corporations to modify their practices to find profits with an deregulated media environment, the notion of neoliberal governmentality in particular fits Current TV's project.

The "employee-client relationship" held between Current TV and its VC2 freelance producers is an example of a "neoliberal model of participation," according to Hands (2011). Hands states that Current TV is attempting to mix neoliberalism with social justice. Current TV is "a socially 'radical' vision within a market context" (Hands 2011: 54). But he sees the radical vision of explicit participation as but a marketing ploy and a reason to acquire non-democratized inexpensive labor. His conclusion is that Current TV is "being disingenuous and disavowing its market roots in pursuit of a 'cool' branding exercise" (Hands 2011: 55). This accusation is supported by examples of how Current TV uses the same rhetoric to encourage explicit participation from the organized public as it does to solicit interest from potential advertisers and investors. If Hands is right, that the conflation of mission and market motives is "disingenuous," then radical change through a mechanism like social entrepreneurship is unlikely. Hands believes that both "social" and "entrepreneurial" can go together but whether it can be "oppositional is at least limited" (Hands 2011: 57). I disagree in the final assessment with Hands and observe Current TV employees with values that mix both the social and the entrepreneurial. Current TV's goal has not be radical change but a cultural intervention into the hegemonic public sphere.

While it might be attractive to identify Current as a "disingenuous" contradiction, Couldry (2010: 24) summons Foucault $(1991,2008)$ to explain how the process of neoliberal governmentality repudiates such accusations of contradiction. Foucault uses the terms governmentality and "advanced liberalism" to describe the process by which the market has been naturalized against which state and society must be compared (Couldry 2010: 24-25). In this calculation, state activity is subjected to the naturalized logic of the market. Thus it is the principle of governmentality that allows "market" and "politics" to fall under the same rubric of "neoliberal democracy." From the perspective of neoliberal proponents this is not a contradiction.

Nevertheless, from the perspective of for-profit and pro-democratic media corporations working on behalf of increased voice in an hegemonic public sphere, the contradiction remains tangible. They might say: “'Democracy' operated on neoliberal principles is not democracy. For it has abandoned, as unnecessary, a vision of democracy as a form of 
social organization in which government's legitimacy is measured by the degree to which it takes account of its citizens' voices" (Couldry 2010: 64).

In a following critical historiographical case study, I will answer questions in reference to neoliberal participation, including: Can there be a co-productive conflation of mission and market, a digital social entrepreneurship, or is it a cooption by pervasive technocapitalism?

\section{Case Study: Current TV}

Current TV has undergone five iterations that if critically mapped exhibit a range of experiments in participation: INdTV (2000-2004), DC (2004-2005), VC2 (2005-2008), Current.com (2007-2009), and, finally, the Hollywood (2009-) phase.

\section{INdTV Phase (2000-2004)}

Before Al Gore was the Chairman of Current TV he was a journalist, environmentalist, and Vice President who oversaw major expansion of federally-subsidized telecommunications. As a student at Yale he wrote about the impact of television on American journalism. As an environmentalist he was influenced by ecological and cybernetic theories of Teilhard de Chardin and Marshall McLuhan. And as a bureaucrat he was engaged in using the federal government to expand communications infrastructure including the internet. These chapters of Gore's past coalesce in his thinking about Current TV. The cybernetic and network infrastructure coupled with concern about citizen participation in media came together in Current TV's mission to use the network effects to democratize media production and resist the tide of media consolidation.

In the years since Bush v Gore, Gore devised a way to use the internet and television in synchronicity to empower a new generation of news producers by providing them incentive to voice their opinions through nonfiction video, while also maintaining interest in how this social, public goal could inform a new business model. As revealed in his book, The Assault on Reason (2007), Gore had become increasingly frustrated by the power of special interest money in US politics and how US media corporations misinform, un-inform, and distract publics from important political issues. Gore rails against conglomerated television networks and finds some possible salvation in the internet and Current TV.

In May of 2004, Gore made a surprise appearance at the National Cable \& Telecommunications Association convention where he and his partner, Joel Hyatt, announced that they had acquired the news and information network NewsWorld International from Vivendi Universal and renamed it INdTV. With their carriage, InDTV was instantly profitable. Hyatt said, "We have bought a property that's making money, a good medium for growing distribution" (Wallenstein 2004). This was Current TV's first phase, INdTV (2000-2004). Gore and Hyatt could see that the internet was going to provide opportunities to model democracy, capitalize on explicit participation, and 
engage viewers in a dialogue about democracy. Both capitalism and activism was suddenly possible.

Financed by high-tech investors, Democratic Party supporters, and venture capitalists, Current TV's mission has been to use the interactivity of the internet to form a business and an active community. In doing this, Gore and his supporters hoped they could add otherwise under-appreciated information to the debate while bringing a disruptive new form of citizen-vetted, amateur produced-yet paid--video journalism to cable television. The motive was bigger than creating a profitable internet and television start-up firm. There is more than a metaphor for democracy, Gore might have thought, in creating a vehicle to bring the new user-production to mass audiences, while encouraging that audience to become producers themselves. Gore and his supporters thought that Current TV could be the catalyst to empower a new generation of engaged citizens while stabilizing and increasing profits. But their mission and market capacities revolved around securing the political and cultural content from the right people.

\section{Digital Correspondent (DC) Phase (2004-2005)}

Current TV's first labor model, circa late 2004, was to train as many as 200 Digital Correspondents (DC) to shoot and edit nonfiction stories from around the world. Each DC was going to be fully employed and given health benefits.

Michael Rosenblum, citizen journalism educator who worked closely with Gore, had an idea: "put them through an intensive training course...like a Peace Corp you know, [and] put them on two-year contracts for minimal amounts of money and essentially create this army of new young bright journalists with video cameras [who] go all around the world and make stuff for next to nothing" (interview, 8/30/2010).

Thousands of people applied for the position. However, by early 2005, the 2000 applicants received a cryptic email stating that the DC program was no more. After months of preparing the lengthy application and interviewing, these would-be DC reporters felt betrayed, and lost hope in Current TV. One DC hopeful, Josh Wolf, wrote an open letter to Gore, stating that Current TV was "in need of maturation before it can begin to truly address its mission" (Wolf 2005). In an interview with me, Wolf emphasized the feeling of abandonment and his concern about Current TV's contradictions between its ideals and practices.

David Neuman, who held executive programming positions at CNN, Channel One, the Digital Entertainment Network, and Disney had a different plan. Neuman, fresh from recent excursions to the ultra-participatory Burning Man festival in the early 2000s, used the radically participatory model of American art and community festival Burning Man to argue against the exclusivity of Rosenblum's DC model by asking, "like Burning Man, why wouldn't we let everybody in who wants to participate?" (interview 4/19/2010). This was the impetus behind the first user-generated television network, Current TV. His plan was to use the internet to crowdsource content, not from a few hundred well-trained professionals but from thousands of less-trained and globally distributed media workers. 
This idea particularly resonated with Gore's mission to democratize media production because it was more inclusive than the DC model. In an interview with Neuman, I critiqued the model by saying: "It doesn't create a living wage for 200 people." To that he replied,

No it doesn't...I didn't think that was really what the company was about, the company was about facilitating the democratic dialogue, the company wasn't about how many full time jobs we can create with benefits in San Francisco for an elite cadre of young creators. In fact, we never intended it to be that. In fact, I wanted to have no full-time employees, really. To me the ideal would have been eBay. ... [M]y desire was, lets have 30,000 people making content for Current. That would be beautiful (interview 4/19/2010)

Andrew Fitzgerald, of Current's Collective Journalism department, agreed with Neuman that the DC plan was not the democratization mandated by Gore, "what you are talking about there is you are creating an elite squad...it is an elite republicanization of media versus a true democratization of media" (interview 5/26/2010).

Current TV eventually abandoned the DC plan, Neuman was invited and hired as president of programming for Current TV, and the Viewer-Created Content (VC2) program was born.

\section{VC2 Phase (2005-2008)}

VC2 was the flagship initiative that led Current TV's project of democratizing media production. It was the goals of the VC2 workers to acquire $100 \%$ of their content from VC2 producers - an unsalaried yet paid freelance and contract labor pool of producers uploading drafts of their content on www.current.tv for purchase by Current TV. Soon after the VC2 project was made public, along with thousands of others, I began participating as a would-be documentary television producer. Current TV's creative executives considered our uploads for purchase. Likewise, our peers could vote on our pod on the online Leaderboard, the highest ranking pod each week would get purchased for $\$ 1000$. Neuman did not get 30,000 content providers but rather us "super contributors" --a group of 50-200 freelance VC2 producers with enough free time and economic resources to produce pods for Current TV. From my engagement with my fellow VC2 producers, I could ascertain that most had a desire for employment within the nonfiction film, television, and internet realms. The Leaderboard, the interactions with the creative executives, and the community we formed in dialogue amongst other VC2 hopefuls, constituted the realm of aspirations and values during the VC2 years.

Current TV employees were tasked with stimulating and aggregating as many VC2 producers as possible. They visited film festivals, university film programs, trade shows, and scoured user-generated content sites for producers of nonfiction content. But they were under-staffed and not acquiring the content they need. In 2008, a new department was created, Outreach, and staffed with 6-9 individuals whose entire mission was to locate new producers. Explicit participation communities formed on current.tv and later current.com around any intriguing new uploaded pods. Comments numbered between 10- 
20 and views around 1000. This made for a dynamic environment for producers but those were not the numbers that brought profits.

Current TV experimented with both the length and timeliness of traditional television. Programmatically, VC2 pods emulated internet videos' short time length and randomness as it shuffled five-minute short docs. Aesthetically, it mimicked internet video with a total running time bar counting off the minutes before the end and the beginning of a new pod. Iconographically, Current TV aligned with symbolism of a digital future with partnerships with Yahoo! and Google which both automatically provided their top searches to Current which programmed a robotic female voice at the top of the hour to speak the top searches. Current TV was one of the first cable networks to originate with a dual platform strategy, Hyatt called it the "two screen experience" (Peterson 2009). Thus, emerging in 2005, at the origin of Web 2.0 digital utopianism, and grounding the network in the location and ideology of the internet, Current TV aligned itself first with internet cultures of participation. However, by the most recent historical period, as you will read, this will change, as the Los Angeles office and professionally produced content triumphed.

The highpoint of VC2 was in 2008, when Current won an Emmy for Interactive Television. Accepting the award Gore said of Current's mission, "We are trying to open up the television medium so viewers can help to make television ... and reclaim democracy." During this period, Neilson's Ratings were not monitoring Current TV. Funded by optimistic venture capitalists that were seduced by Current TV's rhetoric of democratization, this period need not be overly concerned with profit production and results. It was a liberated period of experimentation in which privileged and welleducated employees tried out ideas of how to encourage explicit participation. When that failed they were tasked to figure out how to "lower the bar" to participation, this coincided with the rollout of a new website. The Current.com phase (2008-2009) is marked by the transformation of the website from a user-generated social media site, current.tv, for the VC2 video production community, to a social media news aggregate site, current.com, for granular implicit participation such as news story reposting and commentary.

\section{Current.com Phase (2008-2009)}

Stepping off of a statistic acquired through voluntary survey's with their online users, Current TV considered that $70 \%$ of their young audience was watching the cable network while, at the same time, using a laptop (Peterson 2007). They sought to harness this "twoscreen" practice by giving the viewing laptop users an opportunity to submit stories that may be broadcast at the top of each hour. During the Current.com phase (2008-2009), Current TV advertised that they were going public with an Initial Public Offer (IPO) and they attempted to purchase a well-known news aggregate site, Digg, and desired to sell Current TV to Google (Lacy 2008). These are all data points that suggest that Current TV is strongly aligned with the internet business and discourse. 
During the Current.com phase, Current TV attempted to move from an explicit, or the active produsage or crowdsourcing model, to an implicit form of participation. Current $\mathrm{TV}$, attempting to encourage more submissions, to have more material from which to make better programming, as well as to abide by their principle of democratizing media for all the people, not just freelancer seeking employment in the media production, sought to "lower the bar" to being able to participate. I recall a moment in 2007 when Current TV, lead by Vice President of Strategic Partnerships, Chloe Sladden, now working on TV Partnerships for Twitter, proposed a political question and requested video blog-like answers. Sladden wrote me personally, asking me to submit video. I went out to Venice Beach, CA., where I lived, and quickly produced eight videos on a range of issues. This project was called Viewpoints. Much easier than producing and editing a documentary shot in Cyprus with Iraqi refugees, this project required only an opinion and an extremely rudimentary Flip camera (which Current TV sent me), when the VC2 program eventually was cut, the "democratization" continued in this way of lowered technicality, investment, and reward.

Overlapping both the VC2 and the current.com phase was Current TV's TV Free Burning Man project that illustrates the open-source origins of current.com as well as the entrepreneurial freedom during this period. Burning Man is an explicitly participatory event where many people who labor in the digital creative industries work out collaborative utopias that make their way into the social networking software and platforms they make and ask us to populate with our creative surplus, communal energy, and visually expressive humanity. The techno-culture historian Fred Turner states that Burning Man is a "sociotechnical commons"- the cultural infrastructure for the digital media industries of California (Turner 2009). Burning Man influenced VC2 but also their social media website, current.com. Much like Burning Man, each project is an attempt to draw knowledge from the crowd and transform spectators into active producers--as idealistic and impossible as that may seem.

From 2005 to 2008, Current's website was http://www.current.tv. It was a space dedicated for VC2 producers to upload and critique short documentaries. In 2008, Current TV's upper management decided that this was too elitist and they wanted more traffic so they put together a group of marketers, engineers, and creative executives to envision the new website, current.com. This site was not only for producers but for anyone to contribute anything. One of those creative executives, Justin Gunn, went into the first meeting to brainstorm current.com and said:

"We are going to start with the organizational principle of Burning Man, it is a very light, lean organization. I could be wrong here but there is something like 12 full-time employees around the year everything else is all volunteer labor. But they build the structure, they set the rules, they define the parameters and then they invite anyone, anyone to come and do whatever they want..." (interview 8/2/2010).

Using their shared interests in participatory community, self expression, and technology as a platform for dialogue-as well as their proximal offices mere blocks from each other in the Silicon Valley outpost of SoMa in San Francisco- producers at Current TV and 
organizers of Burning Man began to scheme about a more dynamic relationship. TV Free Burning Man was a result. Combining professional and amateur field production with a televisual aesthetic of first person documentaries and tone poems, the for-profit mass media television firm Current TV produced content live from Burning Man for four years, 2005-2008. Considering Burning Man's imperative to avoid all forms of commercialization and the strict media permitting process for amateurs to even use a still camera at Burning Man, TV Free Burning Man is a testament to the shared ideals and aesthetics of Current TV and Burning Man. The two institutions bonded around the shared mission of creating the conditions for explicit participation.

Current.com was modeled after the participatory ethos of Burning Man, but is also an attempt to create a popular website that could support the IPO advertisement with quantitative numbers about the brand's traffic. During the current.com phase, VC2 content was slowly phased out of the regular programming. Mark Rosenthal, ex-COO of MTV Networks, took over the role as CEO of Current TV, replacing Hyatt. President of Programming David Neuman who had incubated the first few experiments in creating a user-generated cable television network also left. The mission of explicit participation ended when this phase concluded. The most material manifestation of the shift away from explicit participation was the firing of hundreds of workers from the outreach, editorial, and amateur acquisitions departments on November 2007 and 2008. With these employees gone, it was clear, so was the VC2 program, and with it Current TV's most legitimate project of "media democratization."

As the brief review of five years of history at Current TV should display, a suite of differing, sometimes contradictory, and other times agreeable values and practices emerged, remained, or were abandoned. For four years (2005-2008) Current TV, attempted to integrate the audience into the programming. The internet-centric venture capitalist investment funds were strongly present during this time, as was Al Gore as a brand with his recent Emmy, Oscar, and Nobel Peace Prize. "Democratization" was a trending topic in Web 2.0 digital entrepreneurship. Social news site Digg and social video sites Blip, Revver, and YouTube all used the term "democratization" in their online "about" page or stated it publically. Current TV's relationship with Comcast, where the cable behemoth owns $10 \%$ of the network, insures a steady stream of profits from subscription fees. Thus during this idealistic period, Current TV was guaranteed profitability despite the absence of lucrative commercial deals. This economic consistency combined with the $\$ 70$ million raised through equity and venture capitalist investment, enabled Current TV to experiment wildly between 2005-2008 after which the investors began to agitate for returns on their investment, instigating the change in programming strategy away from the internet to the cable property. It was not until the VC money ran thin and the commercial sponsorship remained low that Current TV abandoned the more radical aspects of explicit participation and democratization.

\section{Hollywood Phase (2009-today)}

The most recent phase, which I will call the Hollywood phase (2009-today), describes Current TV as undifferentiated from other non-fiction cable networks, such as the 
networks under the Discovery Communications conglomerate. Current TV moved towards profiting off of the cable television property by the production of hit television programs made by professional producers. The website was not a site for user-generated video content as it was as current.tv during the VC2 Phase, nor was it a space for the uploading of news stories as it was in the current.com Phase. In the Hollywood Phase, the website is for advertising for the cable television programming produced in-house or by professional producers. When once the network was all about the amateurs, Current TV, in this phase, began to rely upon its celebrity connections to bring in audiences. For example, beginning in June 2011, Keith Olbermann, the progressive news anchor previously on MSNBC, began at Current TV.

Current TV still uses some of the democratization rhetoric along with this professionalization. Will Wright, inventor of the virtual world Sims franchise, produced software for Current TV with which the audience could create storylines for inclusion in the fictional program Bar Karma. My informants working on Bar Karma say that the software does not work and the inclusion of audience participation in Bar Karma is "window-dressing" and "a joke." Current TV holds onto the VC2 branding but instead of non-fiction news stories by amateurs, Current TV calls VCAM ("Viewer-created ad messages") VC2. One Current TV employee "shudders" when she sees how Current TV uses the term VC2 not as a marker of media reform but as a commercial category. Thus Current TV is making a valiant attempt to professionalize and become a mature cable news and non-fiction television network while retaining none of the original practices but some of the rhetoric.

\section{Convergence, Crowdsourcing, and Neoliberal Participation}

In light of this critical history of Current TV, in this final section I will return to the core questions of each of the participatory theories.

\section{Convergence and the Politics of Consumerism}

Current TV, its founders and early employees, were seriously motivated by political implications. They believed in media democratization and saw Current TV as a tool capable of transforming our practices of media democracy. In historical studies of forms of mass communications and production, from radio to fax machines, and from personal computers to the internet, such digital utopianism is common (Streeter 2011). And yet, the competitive cable television market and investors pressured Current TV in the Hollywood Phase to abandon these politically inflected ideals in favor of projects more assuredly profitable. Thus, political action within consumer culture is truncated by the profit motive. However, in the absence of public initiatives to provoke civic participation, the responsibility for such initiatives falls upon media corporations who have the resources and increasingly the motivation towards social entrepreneurship. Current TV took its social liberal responsibilities seriously but the structuration of market logic eventually forced the migration of their mission through numerous iterations. 
Jenkins abandons the idea that explicit participation is feasible as the driving force for long-term cultural change. He believes that corporations as well as audiences are not going to give up the simplicity nor and the economic potentials of implicit participation. The change Jenkins foresees is "towards consumption as a networked practice" (2006: 244). These "consumption communities" (2006: 245) will subtly but consistently reform the formal social enterprises into firms of greater interactivity, listening, and engagement with organized publics. This is a far cry from a media revolution lead by video citizen journalists and the emergence of internet broadcasting as a decentralized distribution system. Consumption is an undeniable force in our biological and social lives. But it is not the only social process through which we as humans evolve, develop our identities, cultivate our communities, and dialogue through on our way to civic society. For a few years, Current TV created the socio-technical conditions for the development of these para-market capacities.

Jenkins puts the responsibility for generative transformation squarely on the shoulders of the consumption community; he does not make the media firms responsible for progressive social change. He goes onto critique what he calls "critical pessimists" who "exaggerate" and "frighten readers into taking action" (2006: 247) to stop media consolidation, exclusion, and the absence of televisual diversity. These "critical pessimists" focus on impediments, primarily media corporate consolidation. This is only one of the necessary fights, according to Jenkins, which also includes mobilizing for "more participatory media culture" (2006: 248). The evidence from Current TV reveals that explicit form of participation, beyond consumption communities, are possible and formal social enterprises can and do address audiences not only as consumers but also as active citizens.

Along with another of my case studies, the satellite network Free Speech TV, I attended Free Press's National Conference on Media Reform, April 7-9, 2011. FCC chairmen, independent radio and television hosts, activists, and Current TV host Erin Gibson spoke at this important event for the so-called "critical pessimists." There were panels like "Creating and Sustaining Citizen Journalism" which focused on using digital and cable access technologies to generate civic awareness and participation. Robert McChesney, who Jenkins cites as the quintessential "critical pessimist," was a panelist on a roundtable called "Journalism and Democracy: Rebuilding Media for Our Communities" which optimistically focused on how participation in journalism has been democratized. At the NCMR there was no notion of activist implicit participation, clicktivism, slacktivism, or the transformative capacities of "consumption communities" but rather a request for us to awaken and magnify our collaborative and productive potentials to make and manage media. Thus media reformers like Current TV in its VC2 phase are not pessimists. They provide a necessary check on corporate power and mindfully work for greater civic, community, and citizen involvement in media production. The media reform movement confronts but does not collaborate with the media industry while instigating explicit participation by organized publics.

Secondly, firms are responsible for creating the environment for participatory culture. Current TV is an excellent example of a mission-driven for-profit media corporation 
enacting a type of digital social entrepreneurship that shares its distribution platforms, its personnel resources, even its capacity to finance production, into the production of a more participatory media culture. In the absence of a strong public media funding base, such as we do not have in the United States, some social services fall upon the responsibility of corporations. Current TV took it upon itself to create a social justice service within the market economy. As media activists concerned with the prevalence of media democratization, we need to both encourage our grassroots base to continue participating in open-source initiatives while simultaneously demanding access, diversity, openness, and transparency of media corporations and their regulators.

I support attempts to transform industries from within, through collaborative engagement and dialogue with media executives, to identify and operationalize their social responsibilities. Access to these executives is an opportunity to talk with the executives about their social mission. I also advocate for aggressive ideological and practical confrontation with the industries and federal overseers responsible for allocating broadcast and broadband spectrum. The works of Free Speech TV, early Current TV, and Free Press are examples of organizations working for the public's rights to media production. These organizations see audiences as more than consumers, they seek to transform implicit into explicit forms of participation, and create alternative platforms for collaborations while hacking preexisting forms. These pro-social activities attempt to intervene within and influence the hegemonic public sphere, which includes but is also truncated by, the market fundamentalism of neoliberal governmentality.

\section{Crowdsourcing, Professionalization, and the Engineering of Organized Publics}

I have interviewed 20 people who can reasonably be called "online community managers" whose daily task is to watch, categorize, contact, cultivate, and promote professional/amateur internet video producers. While these are entry-level positions, and ones several Current TV immigrants took after leaving Current TV at internet video startups, they are key cultural aficionados, defining what is socially relevant, promotable, or capable of running advertisements against and within. Their taste is influenced by their age and education. Most are under 25, holding BAs from some of the most exclusive universities, and privileged enough to be financially backed to be able to take unpaid internships, while dabbling in internet video production. The taste-based filtering done by online community managers is one example of vetting that includes, in these rather small firms, executives, vice presidents, CEOs, and boards. This engineered meritocracy is recursively fueled by an echo chamber that includes implicit participation from the crowd in the form of comments and "likes." Such gatekeeping and vetting form important processes by which an amateur public is professionalized. Online community managers, act as creative advisors, cultural brokers, agents, and financiers for internet video producers. They tempt explicit producers with monetization and entry into exclusive castes such as "getting on TV," a consistent bait from Current TV.

Howe (2008) and my own work confirm the theory that explicitly participating organized publics can be provoked into existence by formal social enterprises but not without the use of considerable personnel resources. Current TV found this out the hard way as they 
lost the DC contributors, marginalized the $\mathrm{VC} 2$ producer community in the transition from the explicit current.tv to the implicit current.com model, and failed to engage the audience in Bar Karma. Online community managers need to function as gatekeepers and greeters.

Howe considers crowdsourcing at Current TV as explicit participation requiring "a robust community of people with deep and ongoing commitment to their craft, and most importantly, to one another" (Howe 2008: 180). This is not the collective intelligence generated by implicit, involuntary, accidental, or algorithmically ordered participation. Crowdsourcing platforms and applications will not operate without organized publics, but as Howe discovered, crowdsourcing also needs fulltime formal social enterprise employees personally encouraging the organized public. An organized public in an explicit crowdsourcing relationship to a formal social enterprise requires feedback, tasks, and rewards (Fish et al. 2011). Current TV originally failed in this regard, according to Howe, but I had a different experience.

Howe says that in the summer of 2007, current.com was a "ghost town." As one of the ghosts in that town I found it lively, educational, and collaborative as both Current TV employees and a small but vibrant and vocal group of $\mathrm{VC} 2$ producers discussed the technical and contentual issues of our pods. In public comments sections we argued about which pods deserved broadcast. We openly hypothesized the virtues and hopes of Current $\mathrm{TV}$. Upon uploading my first pod to current.tv, I received instant reaction from the creative executives from Current TV, emails soon followed backed up by phone calls and an invitation to visit the LA offices and studio. I became a "super contributor," one of the small percentage that uploads most of user-generated content. This republic of matriculation and meritocracy appeared opaque to some for a company billings itself as democratically orientated.

Robin Sloan, Current TV's web strategist, and now working for Twitter on social applications for television, made a prescient remark about Current TV's relationship to the organized public stating, "We established vertical relationships with each individual producer. ... What we should have done was create a horizontal relationship with the community" (Howe 2008: 202). He was correct, after I had cultivated a relationship with two Current TV creative producers who could purchase and commission my pods, my curiosity in arguing within the community faded. My motivation became financial and professional as I become a more valuable $\mathrm{VC} 2$ producer. With interest in the community fading, Current TV's "crowdsourcing" looked more like a traditional freelancing operation as opposed to a horizontally organized and explicitly participatory organized public.

Throughout this trial, a community of producers, both within the organized public as well as the formal social enterprise of Current TV, gained expertise and technical skill in the monetization of internet video, crowdsourcing, and social media--these skills they brought to present projects where many make a living and further professionalize the field of internet video production. After being fired by Current TV, many informants have gone on to work at major internet video channels such as Revision3 and The 
Station, news agencies like Al Jazeera and CNN, and social media magnates like Twitter (McGirt 2010). The cover of Fast Company, December 2010-January 2011, featured a photo of Chloe Sladden, who I described previously as once being a Current TV executive and who is now with media partners at Twitter. The article also focuses on Sladden's partner, ex-Current TV employee, Robin Sloan. This Fast Company magazine happened to be on the desk of Al Jazeera's new social media program, The Stream, where ex-Current TV employee Andrew Fitzgerald now works. It is little instances like these that show the impact of this first generation of online community managers who came of age at places like Current TV as well as the networked connections within this culture of media production. Perhaps it was not a direct democracy, but Current TV worked as a meritocracy for the finding of talented young executives and jumpstarting freelance careers in digital video production. A longitudinal study of the work lives of Current TV proves that online community management was a new professional field that began with naiveté and became a business. This illustrates the historical observation made by $\mathrm{Wu}(2010)$, that networked communication systems migrate from open and amateur to closed and profession. A historical analysis of the failures and successes of formal social enterprise crowdsourcing illustrates this historical observation in the realm of television and internet video convergence.

\section{Neoliberalism and Social Entrepreneurship}

Current TV does not employ a democratic approach but rather an employee-client relationship with its explicit participants. Hands categorizes this relationship as a "neoliberal model of participation" (Hands 2011: 63). Online managers at Current TV reluctantly admitted that they were cultivating a small group of producers that were actually "freelancers." Hands does not elaborate on the connection between freelancing and neoliberalism but other authors observe that neoliberal economic policy requires a casual work force without the burden of emotional investment and health benefits associated with fulltime employment (Sassen 1998). Additionally, the creative industries thrive on the free labor of interns, temps, and freelancers hoping to gain access to "cool" jobs (Neff et al. 2005). But while Current TV did employ neoliberal participation it was tempered by the social entrepreneurial vision of explicit participation and the challenges of crowdsourcing. Emitting a live feed from the Nevada desert during Burning Man was an expensive undertaking done not out of a neoliberal impetus but as an experiment in participatory culture and social entrepreneurship.

In an email to me responding to the accusation that Current TV was engaged in neoliberal like activities that exploited participation, Neuman said:

"The VC2 model was created to reify Al and Joel's mission of democratizing television, pure and simple. It was not devised as a way to keep labor costs low, or to make the business operate better as a business, per se. It was a solution for a specific mission and objective at that place and time." (email to author 11/9/10)

Hands is rightfully critical of corporate involvement in public media practices. He writes about the members of the executive floor of Current TV as all mainstream men driven 
singularly by financial concerns. He highlights that Gore is as son of a senator and a millionaire without investigating Gore's in-depth understanding of ecological and computer based cybernetics, the role of journalism in democracy, and Gore's authentic belief in Current TV as a social service. He writes about the ex-President of Programming Neuman as a CNN and NBC executive without mentioning his role at Channel One, the youth educational program streamed into schools throughout the United States, nor his position leading the Digital Entertainment Network, the youth focused dotcom video site focused on provocative issues such as race and gay culture. My point is that human values are variable not singular. Current TV's values are equally divided and complex. Current TV's expressions of neoliberalism were not contradictory with their social liberal values because they were intent in modifying the hegemonic public sphere, itself constituted by market and mission projects and logics.

Hands's final summation is that "a more profound shift in the mode of production and distribution is needed in order to break the constraints of a still dominant technocapitalism" (Hands 2011: 69). I agree, however, Current TV was not selfconceived as antagonistic with mainstream media and only a gentle counter-power. Instead, Current TV is a digital social entrepreneurship, working the ever fluctuating balance between mission and markets, aided by technologies and a variety of forms of participation. My observation is that Current TV's social mission was legitimate while their emphasis on user-production business models was hemmed in by the looming pressures of technocapitalism (Kellner 1993). Perhaps this mission/market hybridity is a sign of the dominating interpellation by the logic of neoliberal governmentality (Foucault 1991) or perhaps it is the necessary methodology for intervening within the hegemonic American public sphere.

\section{Conclusion}

In this article I introduce the term digital social entrepreneurship to describe the mix of market and mission values that appear in the language and actions of employees at Current TV. I show the power of online community managers as gatekeepers and tastemakers. I rehabilitate the notion of media reform to include confrontations with media firms, inviting them to promote participatory culture. Throughout this article, I affirm the importance of diachronic work to challenge simplified theoretical explanations.

Participatory regimes change through time and in accord with new values and constraints. The supremacy of market over mission or mission over market values is variable depending upon the resources and goals of the formal social enterprise and its relationship to the organized public. No single theory and no scholar abstaining from interviews, historical analysis, and participant observation can grasp the variety and complexity of this relationship. Through historical analysis it is possible to overcome the limitations and inaccuracies of speculative and polemic theorizations. This article is not an example of a single theory being used to explain the workings of an entire historically variant entity. Instead, it is an attempt to exhibit the power of participant observation, 
history, and numerous theories to describe the social, political, economic, and technological diversity within any social phenomena.

\section{Limitations and Future Research}

This article is an extension of the model regarding formal social enterprises and organized publics that attempts to describe the variety of internet-enabled forms of participation (Fish et al. 2011). More case studies are necessary to create a taxonomy of participation. More data will enable us to answer the question: What social factors and technical affordances provoke and limit participation?

Like any project, methodological limitations and structures were imposed in order to make veracious arguments. Some limitations, such as testing only the theories of participatory television developed to investigate Current TV, resulted in conclusions that may or may not have potency in cross-cultural research. Thus this theoretical limitation may result in only limited application. Only through a re-application of these critical assessments of crowdsourcing, convergence, and neoliberalism in the context of other similar social entrepreneurs, will these preliminary conclusions be tested.

The limitations of the theoretical approach are paired with the limitations resulting from the small data sample of but a single firm, Current TV. The present research isolates its case study and fails to investigate Current TV as a collaborative node in a network of other social entrepreneurs, participatory television proponents, and media reformers. Current TV has economic partnerships with telecommunications companies and commercial advertisers. To define participation to include only the firm's creation of the conditions for public interaction is a reduction of the depth and breadth of internetenabled participation. For example, forms of participation can include inter-firm relations that may include mergers and partnerships.

This suggested cross-cultural comparative work should utilize a more rigorous ethnographic method than the one used here consisting of a mix of interviews, historical studies, and infrequent observation and participation. Long-term participant observation should be conducted within firms or institutions that mix market and mission with participatory technology tools.

Additionally, while the article has found the pair, implicit and explicit participation, useful, a more fine-grained description of the variety of forms of passive and active, involuntary and voluntary, ways of participation, will be necessary in developing a typology of internet-enabled participation.

This has been a study of but one form of internet-enabled participation, bound to the socio-technical affordances of television and internet video. But the possibilities of participatory culture impact numerous fields and disciplines. Citizen science, open source software communities, and civic planning are all important horizons for citizen participation. Expanding the study of participation into more fields will enable future researchers to begin to document participatory success and failures across numerous 
fields and disciplines. Such future research should have implications far beyond video industries and speak directly to the issues of the role of the citizen in representational democracy itself.

\section{Works Cited}

Benkler, Yochai. 2011. The Penguin and the Leviathan. New York: Crown Business.

Benkler, Yochai and Helen Nissenbaum. 2006. Commons-based Peer Production and Virtue. The Journal of Political Philosophy: Volume 14, Number 4: 394-419

Bruns, Axel. 2008. Reconfiguring Television for a Networked, Produsage Context, Media International Australia Incorporating Culture and Policy, No. 126. (Available online at http://eprints.qut.edu.au/archive/00013002/).

Carpentier, Nico. 2009. Participation is Not Enough. The Conditions of Possibility of Mediated Participatory Practices. European Journal of Communication. 24:4, 407-420.

Caldwell, John T. 2004. Convergence Television: Aggregating Form and Repurposing Content in the Culture of Conglomeration. In L. Spigel \& J. Olsson (Eds.), Television after TV: Essays on a medium in transition (pp. 45-56). Raleigh, NC: Duke University Press.

Comaroff, Jean and John L. Comaroff. 2000. Millennial Capitalism: First Thoughts on a Second Coming. Public Culture, 12:2, 291-343.

Couldry, Nick

2010 Why Voice Matters: Culture and Politics After Neoliberalism. London: Sage.

Fish, Adam, dir.

2007c Secular Iraqi Refugees. Current.

Fish. Adam

2008 Divided Cyprus. Current.

Fish, Adam and Ramesh Srinivasan

2012 Digital Labor is the New Killer App. New Media and Society 14(1): 135-150.

Fish, Adam and Christopher Kelty, Luis F.R. Murillo, Lilly Nguyen, Aaron Panofsky. 2011 Birds of the Internet: A field guide to understanding action, organization, and the governance of participation. The Journal of Cultural Economy.

Foucault, Michel

1991 Governmentality. In the Foucault Effect: Studies in Governmentality. Grahm Burchell, Colin Gordon, and Peter Miller, eds. Chicago: University of Chicago Press. 
Foucault, Michel

2008 The Birth of Biopolitics: Lectures at the College de France, 1978-1979. NY:

Palgrave.

Gore, Al. 2007. The Assault on Reason. New York: Penguin Press.

Hamilton, James. F. and Kristen Heflin. 2011. User Production Reconsidered: From Convergence, to Autonomia and Cultural Materialism. New Media \& Society 1-17

Hands, Joss. 2011. @ is for Activism: Dissent, Resistance and Rebellion in a Digital Age. New York City: Pluto Press.

Harvey, David. 2005. A Brief History of Neoliberalism. Oxford: Oxford University Press.

Heidegger, Martin. 1993. The Question Concerning Technology, in M. Heidegger, Basic Writings, ed D. Farell Krell, London: Routledge: pp 307-41.

Howe, Jeff. 2008. Crowdsourcing: Why the Power of the Crowd is Driving the Future of Business. New York: Crown Business.

Jarzombek, Mark, 1999. A Prolegomena to Critical Historiography. Journal of Architectural Education 52:4, 197-206.

Jenkins, Henry. 2006. Convergence Culture. New York: New York University Press.

Johns, Adrian. 2009. Piracy: The Intellectual Property Wars from Guttenberg to Gates. Chicago: University of Chicago Press.

Keen, Andrew, 2008. The cult of the amateur: how blogs, MySpace, YouTube, and the rest of today's user-generated media are destroying our economy, our culture, and our values. New York: Random House.

Halleck, DeeDee. 2002. Hand-Held Visions: The Impossible Possibilities of Community Media. New York: Fordham University Press.

Kellner, Douglas. 1990. Television and the Crisis of Democracy. Boulder: Westview Press.

Kellner, Doug. 1999. New Technologies, the Welfare State, and the Prospects for Democratization, in Communication, Citizenship, and Social Policy, edited by Andrew Calabrese and Jean-Claude Burgelman. Lanham, Md.: Rowman and Littlefield 1999: 239-256.

Klinenberg, Eric. 2007. Fighting for Air: The Battle to Control America's Media. New York: Metropolitan Books. 
Kperogi, Farooq A. 2011. Cooperation with the corporation? CNN and the hegemonic cooptation of citizen journalism through iReport.com, New Media \& Society, 13: 314329

Lacy, Sarah. Once You're Lucky, Twice You're Good: The Rebirth of Silicon Valley and the Rise of Web 2.0. New York: Gotham Books.

Lanier, Jaron. 2010. You are Not a Gadget. Random House.

Marcus, George. 1995. "Ethnography in/of the World System: the Emergence of MultiSited Ethnography." Annual Review of Anthropology 24: 95-117.

McChesney, Robert. 2008. The Political Economy of Media: Enduring Issues, Emerging Dilemmas. New York: Monthly Review Press.

McGirt, Ellen. 2010. I Want My Twitter TV! Fast Company. December 2010-January 2011, 98-108.

Neff, Gina \& Elizabeth Wissinger \& Sharon Zukin. 2005. Entrepreneurial Labor among Cultural Producers: Cool Jobs in Hot Industries, Social Semiotics, 15: 307-334.

Petersen, Laurie. 2007. New Current.com Creates Integrated Two-Screen Experience Monday, October 15, 2007, 6:00 AM

http://www.mediapost.com/publications/index.cfm?fa=Articles.showArticle\&art_aid=69 180

Ritzer, George and Nathan Jurgenson. 2010. Production, Consumption, Prosumption: The Nature of Capitalism in the Age of the Digital "Prosumer." Journal of Consumer Culture. 10(13) 13-26

Sassen, Saskia. 1998. Globalization and its Disconnects. New Press.

Schafer, Mirko Tobias. 2011. Bastard Culture! How User Participation Transforms Cultural Production. Amsterdam: Amsterdam University Press.

Shirky, Clay 2010. Cognitive Surplus: Creativity and Generosity in a Connected Age. London: Penguin Press.

Streeter, Thomas. 1996. Selling the Air: A Critique of the Policy of Commercial Broadcasting in the United States. Chicago: University of Chicago Press.

Streeter, Thomas

2011 The Net Effect: Romanticism, Capitalism, and the Internet. NY: New York University Press. 
Tapscott, D. and Williams, A. 2006. Wikinomics: how mass collaboration changes everything. NY: Portfolio.

Terranova, Tiziana. 2009. Free Labor: Producing Culture for the Digital Economy. http://www.electronicbookreview.com/thread/technocapitalism/voluntary

Turner, Fred. 2009. Burning Man at Google: A Cultural Infrastructure for New Media Production. New Media \& Society, 11: 1-2: 145-66.

Wallenstein, Andrew. 2004. Gore enters TV race with news net buy, Hollywood Reporter, May, 5, 2004.

Wolf, Josh. 2005. Open Letter to Al Gore http://joshwolf.net/blog/2005/10/20/an-openletter-to-al-gore/

Wu, Tim. 2010. The Master Switch: The Rise and Fall of Information Empires. Knopf Doubleday Publishing Group. 